\section{An incidental case report of Disc Battery Ingestion in a child with congenital hearing loss}

\author{
Betsy Mathew ${ }^{1 *}$ and Ananta Jois ${ }^{2}$ \\ ${ }^{1}$ Consultant Pediatric Intensivist, GG Hospital,Trivandrum, India \\ ${ }^{2}$ Physician Assistant, PICU, GG Hospital, Trivandrum, India
}

\section{Introduction}

Foreign body ingestion in children is a serious problem encountered among children. Approximately $80 \%$ of cases of foreign body ingestions occur in children between the ages of six months and three years [1]. Button battery ingestion occurs at an estimate rate of ten in one million people per year, a small group of which are retained in the esophagus and later become complicated [2]. Button battery ingestion can lead to esophageal perforation and death within hours if not appropriately diagnosed [3].

\section{Case report}

A 3 years old male with congenital hearing loss (Right sided hearing aid device in situ) was rushed to the Emergency Room of our hospital with complaints of accidental ingestion of a disc battery from his own hearing aid device. The mother noticed that the device was not functioning and when the same was asked to the child, he accepted the ingestion occurred few minutes ago. No specific symptoms were observed. General \& systemic examination were normal. Routine blood investigations were normal. Erect abdominal X -ray showed the round, radio-opaque object in oesophagus. He was subjected for an emergency endoscopic removal of the foreign body (OGDscopy) by the medical gastroenterology team. Post procedure, child was observed in pediatric intensive care unit. Supportive treatment with antiemetic, antacid, antibiotic given and was discharged in 24 hours. Follow up after one month for voice changes, altered food habits, etc was normal.

\section{Discussion}

Button(Disc) batteries are small, coin-shaped objects that are found in many children's toys, hearing aid devices, remote control,etc. Button batteries are of various sizes. Typically the larger diameter batteries, around $20 \mathrm{~mm}$, cause the most severe complications. These objects may lodge within the oesophagus and cause oesophageal perforation,

\begin{abstract}
More Information
*Address for Correspondence: Betsy Mathew, Consultant Pediatric Intensivist, GG Hospital, Trivandrum, India, Tel: 8281736759; Email: betsymathew001@gmail.com

Submitted: August 09, 2021

Approved: August 16, 2021

Published: August 17, 2021

How to cite this article: Mathew $B$, Jois $A$. An incidental case report of Disc Battery Ingestion in a child with congenital hearing loss. J Adv Pediatr Child Health. 2021; 4: 073-074.

DOI: 10.29328/journal.japch.1001037
\end{abstract}

Copyright: @ 2021 Mathew B, et al. This is an open access article distributed under the Creative Commons Attribution License, which permits unrestricted use, distribution, and reproduction in any medium, provided the original work is properly cited.

\section{(D) Check for updates \\ (.) OPEn ACCESS}

tracheo-esophageal fistulas, and haemorrhage from arterial fistulization. Button battery ingestion can cause injury by 3 mechanisms:

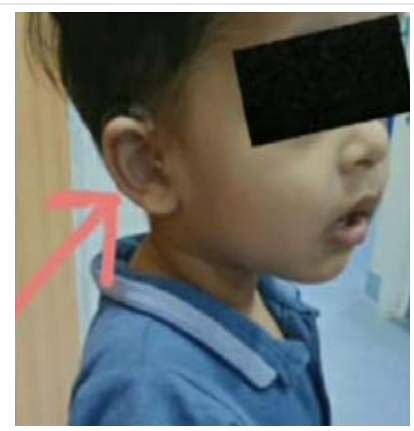

Figure 1: Child with right sided hearing device.

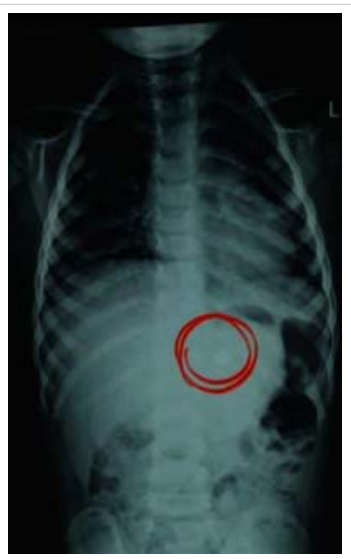

Figure 2: Abdomen X-ray (erect) showing the foreign body. 


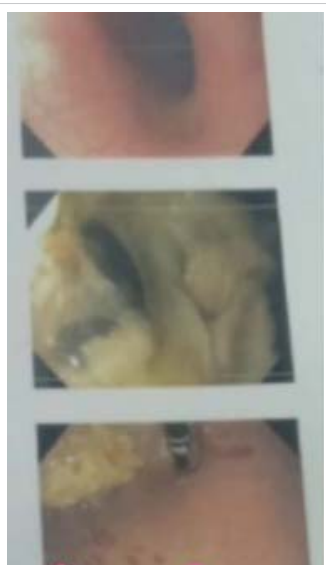

Figure 3: Upper Gastrointestinal Endoscopy images.

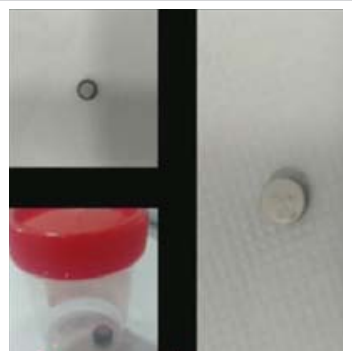

Figure 4: Button battery $<20 \mathrm{~mm}$

(1) Leakage of caustic alkaline electrolyte

(2) Ischemic necrosis caused by direct pressure

(3) Production of external electrolytic current that hydrolyzes tissue fluids creating hydroxide at the negative pole [4].

The oesophagus is susceptible to foreign body retention because of its anatomic areas of narrowing and weak peristalsis. Significant oesophageal damage has been noted as early as two hours post ingestion [5]. Though both coins and button batteries present as round radio opaque objects on chest radiograph, button batteries are easily distinguished by their characteristic double-rimmed appearance in the radiograph [6].

As ingested button batteries can suddenly cause airway compromise, initial management includes airway assessment. Once airway stability is confirmed, further management includes broad-spectrum antibiotics to cover oral flora and immediate removal of foreign body to prevent further damage to the oesophagus. Following removal, patients may require an esophogram to evaluate for oesophageal stenosis and fistula formation. If there are any associated voice changes or stridor, patients will require flexible laryngoscopy to evaluate for vocal cord paresis [7]. Therefore, button battery related accidents may be avoided by many ways. This is done by keeping away household items that contain button batteries out of reach from children, avoid buying toys which require such batteries, check on toys with button batteries \& ensure tightened battery covers, keep spare batteries locked away.

\section{Conclusion}

Early detection is the appropriate management for button battery ingestions in children [8]. A multidisciplinary approach is always helpful while handling children with button battery ingestions. Even after removal of the battery from the esophagus, there may be ongoing evolution of the injury for up to several weeks thereafter, placing patients at risk for a catastrophic aortoesophageal fistula or other severe sequelae [9]. Hence, parents need to be watchful and thereby prevent children from having access to button batteries.

\section{References}

1. Cheng $\mathrm{W}, \mathrm{Tam} \mathrm{PKH}$. Foreign-body ingestion in children: experience with 1,265 cases. J Pediatr Surg. 1999; 34: 1472-1476.

PubMed: https://pubmed.ncbi.nlm.nih.gov/10549750/

2. Alam E, Mourad M, Akel S, Hadi U. A Case of Battery Ingestion in a Pediatric Patient: What Is Its Importance? Case Rep Pediatr. 2015; 2015. 345050.

PubMed: https://pubmed.ncbi.nlm.nih.gov/25692063/

3. Marshalla J, Williamson K. Prolonged Esophageal Button Battery Impaction in a 15 Month-Old: A Case Report. J Fam Med Dis Prev. 2016; 2: 044.

4. Centers for Disease Control and Prevention. Injuries from Batteries among Children Aged Less Than 13 Years- United States, 1995-2010. MMWR. 2012; 61: 661-666.

5. Litovitz T, Whitaker N, Clark L, White NC, Marsolek M. Emerging batteryingestion hazard: clinical implications. Pediatrics. 2010; 125: 1168-1177. PubMed: https://pubmed.ncbi.nlm.nih.gov/20498173/

6. Tanigawa $T$, Shibata $R$, Katahira N, Ueda $H$. Battery ingestion: the importance of careful radiographic assessment. Intern Med. 2012; 51: 2663-2664.

PubMed: https://pubmed.ncbi.nlm.nih.gov/22989846/

7. Jatana KR, Litovitz T, Reilly JS, Koltai PJ, Rider G, et al. Pediatric button battery injuries: 2013 task force update. Int J Pediat Otorhinolaryngol. 2013; 77: 1392-1399.

PubMed: https://pubmed.ncbi.nlm.nih.gov/23896385/

8. Thabet MH, Basha WM, Askar S. Button Battery Foreign Bodies in Children: Hazards, Management, and Recommendations. Biomed Res Int. 2013; 2013: 846091.

PubMed: https://pubmed.ncbi.nlm.nih.gov/23936851/

9. Leinwand K, Brumbaugh DE, Kramer RE. Button Battery Ingestion in Children: A Paradigm for Management of Severe Pediatric Foreign Body Ingestions. Gastrointest Endosc Clin N Am. 2016; 26: 99-118. PubMed: https://pubmed.ncbi.nlm.nih.gov/26616899/ 